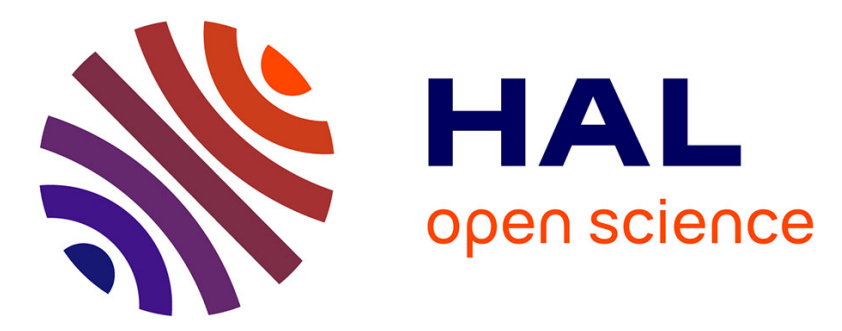

\title{
Influence of the Adsorbent Material in the Performances of a Micro Gas Preconcentrator
}

El Hadji Malik Camara, Philippe Breuil, Danick Briand, Laurence Guillot, Christophe Pijolat, Jean-Paul Viricelle, Nicolaas F de Rooij

\section{- To cite this version:}

El Hadji Malik Camara, Philippe Breuil, Danick Briand, Laurence Guillot, Christophe Pijolat, et al.. Influence of the Adsorbent Material in the Performances of a Micro Gas Preconcentrator. AIP Conference Proceedings, 2009, 1137 (1), pp.323-326. 10.1063/1.3156537 . emse-00494396

\section{HAL Id: emse-00494396 \\ https://hal-emse.ccsd.cnrs.fr/emse-00494396}

Submitted on 29 Jun 2010

HAL is a multi-disciplinary open access archive for the deposit and dissemination of scientific research documents, whether they are published or not. The documents may come from teaching and research institutions in France or abroad, or from public or private research centers.
L'archive ouverte pluridisciplinaire HAL, est destinée au dépôt et à la diffusion de documents scientifiques de niveau recherche, publiés ou non, émanant des établissements d'enseignement et de recherche français ou étrangers, des laboratoires publics ou privés. 


\title{
Influence of the Adsorbent Material in the Performances of a Micro Gas Preconcentrator
}

\author{
el hadj it Malick Camara(1,2), Philippe Breuil(1), Danick Briand ${ }^{(2)}$, Laurent \\ GuILlot $^{(2)}$, CHRISTOPHE PIJ OLAT ${ }^{(1)}$, J EAN-PAUl VIRICELle ${ }^{(1) *}$, NiCOLAAS DE ROOIJ ${ }^{(2)}$
}

(1) Ecole Nationale Supérieure des Mines de Saint Etienne, Centre SPIN ; Département MICC ; LPMG UMR CNRS 5148 ; 158 Cours Fauriel ; 42023 Saint-Étienne Cedex 2, France

(2) Institute of Microtechnology, University of Neuchâtel J aquet-Droz 1, PO Box 526, CH 2002 Neuchâtel, Switzerland Collaboration

\begin{abstract}
This paper presents the evaluation of different adsorbents for the improvement of the performances of a gas preconcentrator by targeting the adsorption of a large range of volatiles organics compounds (VOCs) The objectives of this work are to find the adequate adsorbent for a given gas target in specific experimental conditions and to select an efficient deposition process. Results related to the characterization of carbon nanopowders, carbon nanotubes (single walled (SWCNTs) and multi walled (MWCNTs)) and polymer (Tenax TA) for the development of a device for benzene preconcentration are reported. These results provide guidelines to define the right adsorbent for the preconcentration of benzene according to some specific criterions such as a large specific surface, a high adsorption capacity and low desorption temperature.

Keywords:

Carbon Nanopowder, Carbon Nanotubes, Tenax TA, Benzene, Gas sensors, Preconcentrator. PACS:

01.30.Cc, M 81.07.-b, 81.07.De, 82.35.-x, M 89.60.-k
\end{abstract}

\section{Introduction}

In the field of analytical techniques, the pre-processing of the gases is generally a very important step [1], especially to get a preconcentration effect in order to increase the sensitivity of the detection [2]. Indeed, in some applicative environments the concentration of gas is too small and therefore a preconcentration unit at the entrance of the analytical device is required. When a preconcenrator is used, the gas mixture to be analyzed flows through it and is accumulated during some time, then the mixture is desorbed by a temperature pulse and brought to the detector [3].

Requisite specifications, such as small system size, high performance, low power budget, and quick time response lead to the micro-fabrication of the key components of the analytical systems. Moreover, the miniaturization of the preconcentrators leads to superior heating rates, reduced power consumption and allows its integration in portable miniaturized analytical instruments, such as micro gas chromatographs and ion mobility spectrometers [4]. In a previous study [5, 6], a gas pre-concentrator based on micro-channel technology in porous silicon filled with carbon nanopowders dispersed in a fluidic solution have been developed. The present work aims to improve the performances of this device, with new

\footnotetext{
* Corresponding author : viricelle@emse.fr
} 
approaches in the choice of materials, the realization of the devices and their operation. A series of alternative materials such as polymers, carbon nanotubes, whose surface areas, pores-size distributions, and structures can be varied to serve as conformal adsorbents, were evaluated for the improvement of the performances of the preconcentrator and to enlarge the applications by targeting the adsorption of a wider spectrum of VOCs [7].

The devices in this study have been developed targeting the preconcentration of benzene. This gas is considered as a representative for several types of applications relevant from atmospheric pollution control (BTEX compounds).

\section{Fabrication}

\section{II.1. Micro-channels realization}

Micro-channels with three different designs have been realized with standard etching process as showed in Figure 1.

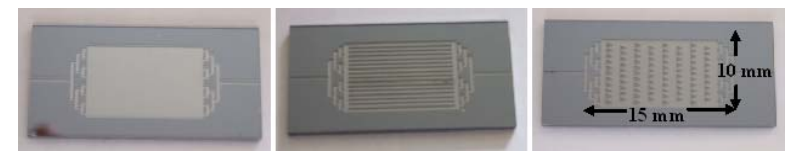

Figure 1: Schematic top view of the "Neutral", "Straight" and "Zigzag" designs, from left to right.

Following a photolithographic step with a thick photoresist, the inlet, outlet and reaction chamber of the micro-channel are DRIE etched in the silicon wafer to a depth of $325 \mu \mathrm{m}$ (Figure 2b). In order to improve the adhesion of the adsorbent that will be deposited afterwards in the micro-channels, $25 \mathrm{~nm}$ of thermal oxide were grown to make them become hydrophilic. Finally, the micro-channels were sealed with a Borofloat glass wafer by anodic bonding (Figure 2c) and diced according to the dashed line showed in Figure $2 \mathrm{c}$ revealing the inlet and outlet for the fluidic connectors. In same case, the glass cover was sealed after the adsorbent deposition.

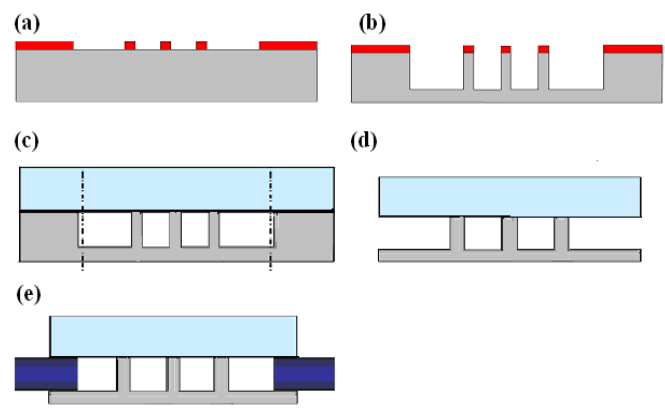

Figure 2: Fabrication process of the preconcentrator, which is illustrated here with the "Straight" type design.

\section{II.2. Micro-preconcentrator implementation}

In order to have an autonomous component, for either the thermal treatments of the adsorbent materials and the desorption of trapped gases, a platinum heater is integrated on the backside of the device by screen printing and the electrical connections are made with gold wires pasted on a platinum lacquer. This heating element is used to heat the device at temperatures up to $5 \mathrm{OO}^{\circ} \mathrm{C}$ with a very homogeneous distribution of the temperature considering the good thermal conductivity of the silicon, as it was reported in our previous work [6].

The adsorbent insertion in micro-channels has been realized by two methods. The first one is a deposition using a fluidic solution [5], and the second one consists to deposit the adsorbent in a paste form before the sealing of the glass cover. It should also be noted that the choice of the deposition method is closely related to the adsorbent nature. For example, since the metallic capillary used as fluidic connection have an internal diameter of $220 \mu \mathrm{m}$, the microchannels can not be filled using a fluidic solution with Tenax particles which have a size between 200 and $250 \mu$ m.

Once the devices filled with the adequate adsorbent material, the fluidic connections are made with metallic capillaries (steel) having $220 \mu \mathrm{m}$ of internal diameter and fixed with ceramic 
cement using a special procedure so as not to block the connectors during the sealing (Figure 2e).

\section{Results and discussion}

The activation of carbon is an oxidizing reaction to release internal porosity created during the carbonization, to expand the pores and to create new micropores. This step must be controlled to avoid the total elimination of the carbon structure as the activation at high temperature (up to $900^{\circ} \mathrm{C}$ ) under oxygen can cause the total disappearance of carbon structure. That is why we have done the activation of carbon nanopowder at $500^{\circ} \mathrm{C}$ during 3 hours in presence of oxygen.

\section{III.1. Specific area measurement}

The first tests were especially dedicated to the measurement of the specific area of the selected adsorbent materials namely carbon nanopowder, carbon nanotubes (SWCNTs, MWCNTs) and at last a polymer (Tenax TA) by nitrogen adsorption using the BET method. These results show that the specific area of the activated carbon nanopowder and the SWCNTs nanotubes are higher than the other three adsorbents (Table 1).

Table 1: Specific area and particle size of different adsorbents.

\begin{tabular}{|l|ll|l|}
\hline \multicolumn{1}{|c|}{ adsorbent } & \multicolumn{2}{|c|}{ specific area $\left(\mathrm{m}^{2} / \mathrm{g}\right)$} & particle size $(\mu \mathrm{m})$ \\
\hline Carbon nanopowder & 99 & $+/-1$ & 0.1 \\
\hline Activated carbon nanopowder & 490 & $+/-8$ & 0.1 \\
\hline SWCNTs & 399 & $+/-5$ & 2 \\
\hline MWCNTs & 21 & $+/-1$ & 5 \\
\hline Tenax TA & 35 & $+/-2$ & 250 \\
\hline
\end{tabular}

However, a large specific surface does not mean necessarily a large adsorption capacity because the latter is closely related to the degree of affinity between the adsorbent and adsorbed gas. So the best solution is to evaluate the adsorption capacity of these adsorbents towards to benzene.

\section{III.2. Benzene adsorption}

The second series of experiments concern the evaluation of the adsorption capacity of the adsorbents by Temperature Programmed Desorption (TPD) technique coupled with a mass spectrometer.

The capacity of adsorption for benzene of the four adsorbents has been evaluated in similar conditions and in presence of humidity.

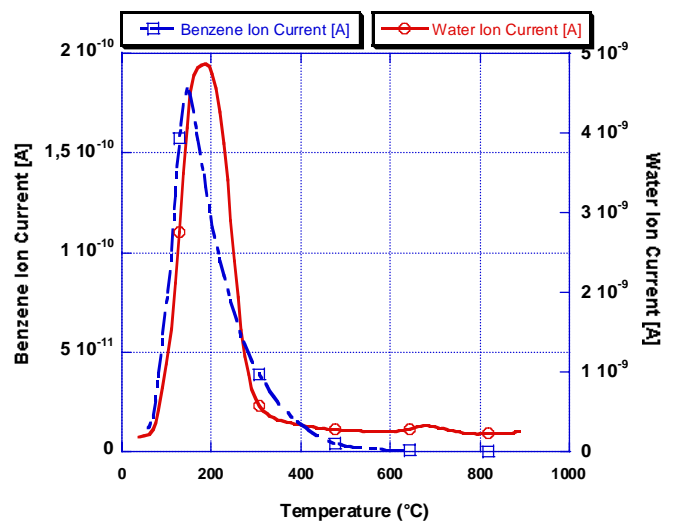

Figure 3: TPD spectrum of Carbon nanopowder after benzene adsorption.

On the one hand, there is a significant desorption peak of water with the activated carbon nanopowder unlike the three other adsorbents which have a low affinity with water vapor. This result reflects a higher decrease of the adsorption capacity of the actived carbon 
nanopowder in a presence of water which is very harmful for the experimentation in ambient air.

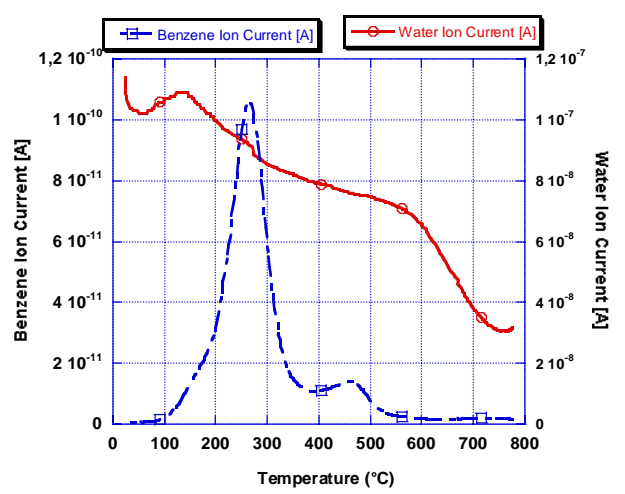

Figure 4: TPD spectrum of SWCNTs after benzene adsorption.

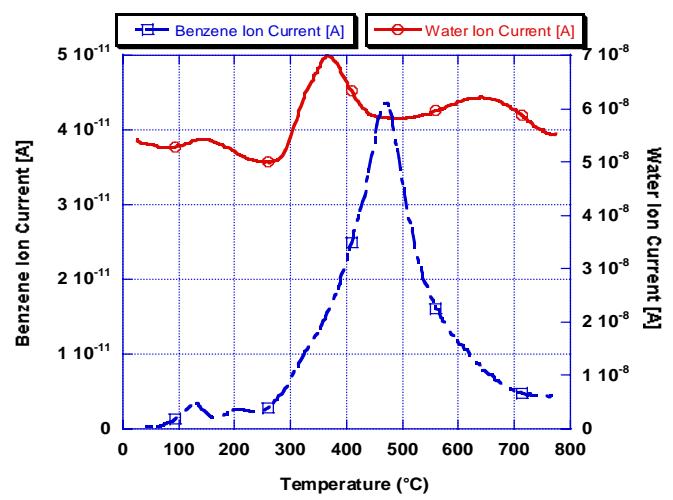

Figure 5: TPD spectrum of MWCNTs after benzene adsorption.

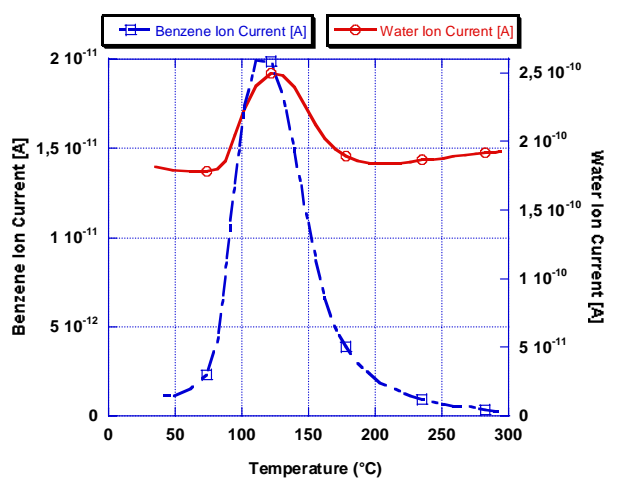

Figure 6: TPD spectrum of Tenax TA after benzene adsorption.

On the one hand, there is a significant desorption peak of water with the activated carbon nanopowder unlike the three other adsorbents which have a low affinity with water vapor. This result reflects a higher decrease of the adsorption capacity of the actived carbon nanopowder in a presence of water which is very harmful for the experimentation in ambient air.

On the other hand, the benzene desorption peak obtained with the activated carbon nanopowder and SWCNTs is about 5 times higher than the one obtained with MWCNTs and Tenax TA. This demonstrates a strong affinity of these two compounds with benzene (Figures $3,4,5$ and 6).

However, it should be noted that the temperature of the maximum amplitude of the desorption peak varies with the adsorbent material. It is estimated at about $120,180,280$ and $490^{\circ} \mathrm{C}$ respectively for Tenax TA, activated carbon nanopowder, SWCNTs and MWCNTs, respectively. The high desorption temperatures of the MWCNTs manifests an important 
activation energy of the desorption synonym with a strong link between the adsorbent and adsorbed gas which is bad for the reduction of the power budget and also for the reliability of the device.

\section{III.3. Experiments with micro gas preconcentrator}

The last experiments have been devoted to the demonstration of the preconcentration effect of these adsorbents when inserted in silicon micro-channels.

Our previous studies $[5,6]$ allowed us to determine the optimal conditions of operation of the micro gas preconcentrator such as an adsorption flow of $10 \mathrm{~L} / \mathrm{h}$, a desorption flow about $2 \mathrm{~L} / \mathrm{h}$, a heating rate of $160^{\circ} \mathrm{C} / \mathrm{min}$, adsorption and desorption time of about 5 minutes. The maximum temperature at the desorption phase was defined according to the results obtained from the TPD experiments. The detector used for these tests is a Photon Ionization Detector (PID).

The preconcentration tests performed with the micro-channels filled with the activated carbon nanopowder confirm that the presence of water vapor reduce intensely the response of the PID. Indeed, the desorption peak obtained after the injection of $250 \mathrm{ppb}$ of benzene in dry air during 5 minutes is twice higher than the one when in wet air at $50 \%$ of relative humidity (Figure 7). These experiments also showed that the temperature of the maximum amplitude of the desorption peak is substantially equal to that one obtained by TPD.

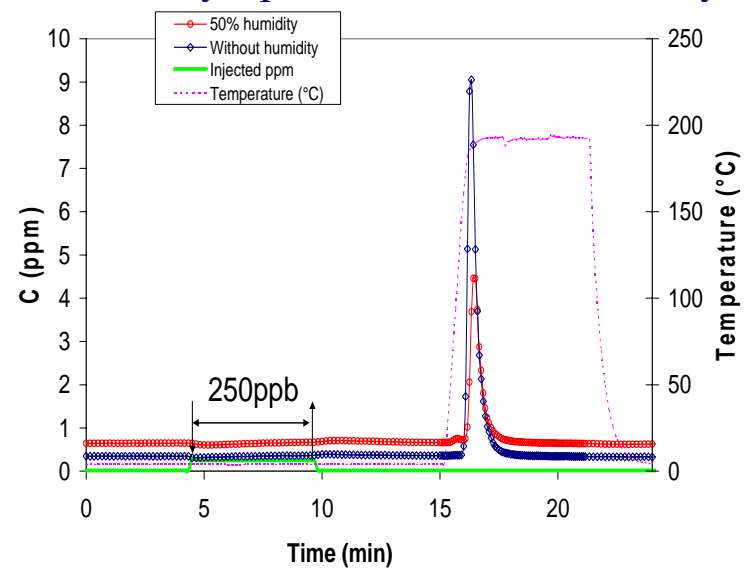

Figure 7: PID response of a silicon micro-channel filled with activated carbon nanopowder with and without humidity, when exposed to $5 \mathrm{~min}$ to $250 \mathrm{ppb}$ of benzene and desorbed during $5 \mathrm{~min}$ at a temperature of $200^{\circ} \mathrm{C}$.

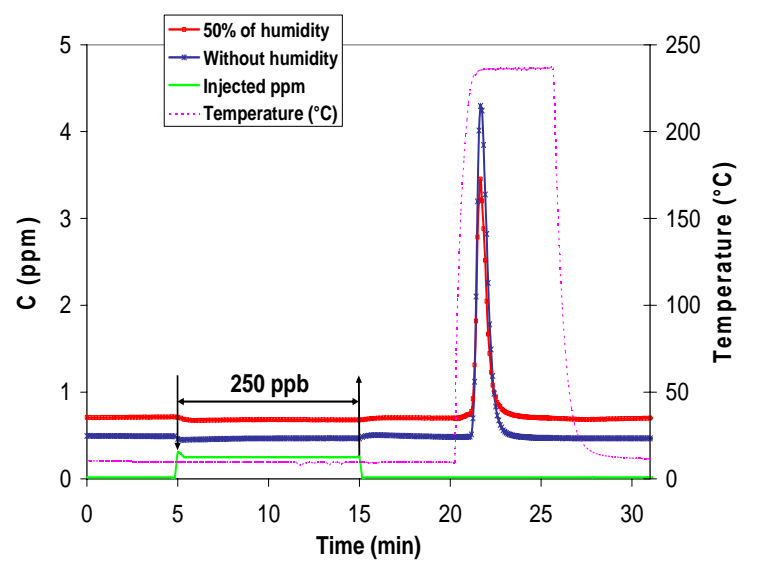

Figure 8: PID response of silicon micro-channel filled with SWCNTs with and without humidity when exposed to $5 \mathrm{~min}$ to $250 \mathrm{ppb}$ of benzene and desorbed during $10 \mathrm{~min}$ at a temperature of $200^{\circ} \mathrm{C}$.

The results obtained with micro-channels filled with SWCNTs have shown that the influence of water vapor in the performances of the micro-preconcentrator is lower than the one filled with activated carbon nanopowder despite a relative humidity of 50\% (Figure 8). We have 
started preconcentration experiments with SWCNTs only recently and some optimization is underway.

\section{Conclusions}

Using TPD experiments and preconcentrator devices, different adsorbent materials have been evaluated. SWCNT has been chosen as the adequate adsorbent for preconcentration of benzene because of its high specific area and adsorption capacity and its low desorption temperature. Our new strategy is to focus on the functionalization of the SWCNTs in order to increase its affinity with benzene molecules.

Moreover, we are currently studying the preconcentration of other volatile compounds such as nitrobenzene. Because nitrobenzene is being strongly adsorbed on activated carbon nanopowder and nanotubes making its desorption very difficult even with a temperature of about $400^{\circ} \mathrm{C}$, alternative materials are required. To this end, the Tenax TA seems the ideal candidate for the preconcentration of nitrobenzene since the latter is completely desorbed below $250^{\circ} \mathrm{C}$.

\section{References}

[1] Th. Becker, St. Mühlberger, Chr. Bosch, V. Braunmühl, G. Müller, Th. Ziemann, K.V. Hechtenberg, Air pollution monitoring using tin-oxide-based microreactor systems. Sensors and Actuators B, 69 (2000) 108-119.

[2] W. A. Groves, E. T. Zellers, G. C. Frye, Analyzing organic vapors in exhaled breath using a surface acoustic wave sensor array with preconcentration : Selection and characterization of preconcentrator adsorbent. Analytica chimica Acta 371 (1998) 131143.

[3] C. Pijolat, D. Briand, Micro-preconcentrator for trace level detection of gases. MST News N 4/ 07 August 2007 pp 15-17.

[4] P. R. Lewis, R. P. Manginell, D. R. Adkins, R. J. Kottenstette, D. R. Wheeler, Recent Advancements in the Gas-Phase MicroChemLab. IEEE Sensors Journal, vol. 6(3) (2006), 784-795.

[5] E.H.M. Camara, C. Pijolat, J. Courbat, P. Breuil, D. Briand, N.F. de Rooij, Microfluidic channels in porous silicon filled with a carbon adsorbent for gas preconcentration. Transducers (2007) pp 249-252.

[6] C. Pijolat, M. Camara, J. Courbat, J-P. Viricelle, D. Briand, N.F. de Rooij, Application of carbon nanopowders for gas micro-preconcentrator. Sensors and Actuators B, 127 (2007) 179-185.

[7] F. Zheng, D. L. Baldwin, L. S. Fifield, N. C. Anheier, Jr., C. L. Aardahl, and Jay W. Grate, Single-walled carbon nanotube paper as a sorbent for organic vapour preconcentration. Anal. Chem. 2006, 78, 2442-2446. 